\title{
CONTRIBUIÇÕES DA RECONSTRUÇÃO RACIONAL DIDÁTICA NO DESENVOLVIMENTO DE CONCEPÇÕES EPISTEMOLOGICAMENTE MAIS ACEITÁVEIS SOBRE A NATUREZA DA CIÊNCIA E DO PROGRESSO CIENTÍFICO
}

\author{
Osmar Henrique Moura da Silva* \\ Carlos Eduardo Laburú** \\ Roberto Nardi***
}

RESUMO: Este estudo insere-se na linha de pesquisa das concepções sobre a natureza da ciência (CNC) no ambiente escolar. Mais especificamente, naquele professor de ciências naturais que diz não se interessar pela filosofia, normalmente se nota uma tendência de se entender e se ensinar uma visão de ciência pronta/acabada e imutável, que influencia diretamente a concepção de ciência nos estudantes. Realiza-se a aplicação de uma reconstrução racional didática no ensino médio cujos resultados vão ao encontro da concepção educacional mais epistemologicamente aceitável sobre a natureza da ciência como algo provisório, variável e controverso.

Palavras-chave: reconstrução racional didática, história e filosofia da ciência, ensino médio.

CONTRIBUTIONS OF DIDACTIC RATIONAL RECONSTRUCTION IN THE DEVELOPMENT OF MORE ACCEPTABLE EPISTEMOLOGICAL CONCEPTIONS ON THE NATURE OF SCIENCE AND SCIENTIFIC PROGRESS

ABSTRACT: This study inserts itself in the research line conceptions on the nature of the science $(\mathrm{CNC})$ in the school atmosphere. More specifically, on that teacher of natural sciences who claims not to be interested in philosophy, it is usually noticed a tendency to understand and to teach a vision of a ready/finished and unalterable science, which directly influences the students conception of science. Discussed here is the application of a didactic rational reconstruction in high school, the results of which are compatible with a more epistemologically acceptable educational conception on the nature of science as something provisory, variable and controversial. Keywords: rational didactic reconstruction, history and philosophy of the sciences, secondary schools.

*Físico (doutor em Ensino de
Ciências e Educação Ma-
temática) do Laboratório de
Instrumentação em Ensino
de Física, Departamento de
Física, Universidade Estadual
de Londrina (UEL),
Londrina-PR, Brasil;
e-mail: osmarh@uel.br
**Docente (doutor em Edu-
cação) do Departamento de
Física, Universidade Estadual
de Londrina (UEL),
Londrina-PR, Brasil;
e-mail: laburu@uel.br
***Docente (doutor em Edu-
cação), Faculdade de Ciên-
cias, Universidade Estadual
Paulista, Campus
de Bauru-SP, Brasil;
e-mail: nardi@fc.unesp.br 


\section{CONSIDERAÇÕES INTRODUTÓRIAS}

A reconstrução racional didática (RRD) foi estruturada e aplicada por Silva (2008) como um passo específico de uma estratégia de ensino cuja função principal é auxiliar o aprendizado racional de conceitos científicos. Um trabalho anterior (SILVA et al., 2008a) apresentou a estrutura dessa estratégia, e outro (SILVA et al., 2008b) mostrou resultados relacionados à preparação dos estudantes para debates racionais baseados na RRD. A RRD divulgada nesses estudos embasa-se no uso da história e da filosofia da ciência como recursos para se elaborar um resumido conto da produção do conhecimento científico considerando-se rivalidades teóricas. A intenção não é obter reconstruções históricas completamente autênticas e sim favorecer o aprendizado de conceitos científicos. Todavia, uma concepção presente nessa elaboração é a de que, ao se ensinar qualquer história da ciência, assim como a própria ciência, ensina-se também, em algum grau, uma filosofia (ALLCHIN, 2004, p. 188; MATTHEWS, 1994, p. 83). Isso destaca a relevância da filosofia da ciência em situações de ensino/aprendizagem das ciências naturais. Sobre a natureza do conhecimento científico, o problema educacional comum pode envolver entendimentos errôneos relacionados à natureza dos modelos científicos, à natureza do método científico, à influência social no conhecimento científico, às controvérsias dentro de uma comunidade científica, e por aí em diante. Mais especificamente, naquele professor de ciências naturais que diz não se interessar pela filosofia, normalmente se nota uma tendência de se entender e se ensinar uma visão de ciência pronta/acabada e imutável, que assim influencia diretamente a concepção de ciência no ambiente escolar (MARTINS, 2006, p. xxv; DELIZOICOV, 1996, p. 183). Relacionando o presente estudo a essa preocupação educacional epistemológica, realiza-se aqui uma aplicação da RRD no ensino médio com o objetivo particular de se investigarem os resultados alcançados favoráveis ao rompimento dessa inapropriada visão de ciência.

\section{RAZÃO DO ESTUDO}

De acordo com Lederman (apud BLANCO \& NIAZ, 1998, p. 327), a concepção dos estudantes sobre a natureza da ciência é influenciada pelos professores e pelo ambiente de sala de aula e, como já alertou Whitaker (1979), essa visão pode incidir fortemente numa assimilação subconsciente ${ }^{1}$. Harres (1999, p. 198) diz que as concepções sobre a natureza da ciência (CNC), do ponto de vista dos estudantes, estão relacionadas aos seguintes aspectos: à consideração do conhecimento científico como absoluto; à ideia de que o principal objetivo dos cientistas é descobrir leis naturais e verdades; à existência de lacunas para se entender o papel da criatividade na produção do conhecimento; à existência de lacunas para se entender o papel das teorias e sua relação com a pesquisa; à incompreensão da 
Contribuições da reconstrução racional didática no desenvolvimento

de concepções epistemologicamente mais aceitáveis sobre a natureza da ciência e do progresso científico

relação indissociável entre experiências e modelos ou teorias. Em ressonância com esses aspectos, no ensino das ciências naturais, vários estudos (PONCZEK, 2009, ps. 297 e 310; PEREIRA \& AMADOR, 2007, p. 213; SILVEIRA \& OSTERMANN, 2002, p. 7; VÁSQUEZ E MASSARENO, 1999, p. 378) ainda comprovam que visões tendenciosas ao empirismo (de caráter falseável ou indutivo) têm indesejadamente sobrevivido, visto que essa é atualmente considerada uma teoria do conhecimento ultrapassada entre epistemólogos, filósofos e historiadores da ciência. Opondo-se ao empirismo clássico, Lakatos (1978, p. 20) comenta que essa teoria passivista do conhecimento sustenta que este é verdadeiro, portanto inquestionável, quando obtido como uma marca impressa pela natureza em uma mente inerte, inviabilizando-se interpretações à luz das expectativas ou teorias. Já uma doutrina filosófica que enfatiza o aspecto empírico-indutivista da ciência é o positivismo lógico defendido pelo Círculo de Viena, tendo R. Carnap (1871-1970) como um dos membros de maior destaque. Segundo essa visão, amplamente criticada por Popper (1972) e outros, os dados que partem da observação e experimentação e que são entendidos como neutros (não contaminados e absolutos), permitem, por indução, estabelecerem-se leis que constituem o conhecimento científico, ignorando-se o papel das ideias e hipóteses geradas pela mente humana como guia para a observação e experimentação. Mais ainda, um termo não tem significado científico se não se referir a um elemento da experiência e, por conseguinte, termos como "elétron", "função de onda", etc., que não se podem obter pela experiência, são problemáticos para os cientistas positivistas ao enfatizarem os fatos empíricos para poderem observar, medir e manipular. Entendimento nesse sentido é válido também para o positivismo de A. Comte (1798-1857), por sugerir que o mundo consiste em fatos positivos ${ }^{2}$ e reais, de fenômenos observáveis, em que o conhecimento científico só deveria existir na descrição desses fenômenos. Esses comentários procuram situar epistemologicamente, ainda que com limitações ${ }^{3}$, os problemas existentes nos entendimentos sobre a natureza da ciência que comumente permeiam o âmbito escolar e que justificam o presente estudo, na intenção de se contribuir para a resolução desses problemas.

\section{A INSPIRAÇÃO NO CONCEITO DE RECONSTRUÇÃO RACIONAL DE LAKATOS (1978)}

Já não é de hoje que a literatura em educação científica tem apontado uma necessidade de se ancorar, quando possível, a quaisquer visões pós-positivistas ${ }^{4}$. Dentre elas, Popper (1972), Kuhn (1974) e Lakatos (1978) podem ser destacadas e que, embora apresentem muitas posições distintas em suas epistemologias, convergem para entendimentos contrários ao do pensamento empírico-indutivista e para a "rejeição da ideia de que a ciência cresce pela acumulação de verdades eternas" (LAKATOS, 1978, p. 9). A RRD deste estudo baseia-se em aspectos da epistemologia de Lakatos $^{5}$ (ibid.), cuja metodologia normativa de elaboração é apresentada na 
próxima seção. Os próximos comentários, no entanto, procuram discutir a inspiração da RRD no conceito de reconstrução racional de Lakatos (ibid.).

Para Lakatos, uma reconstrução racional envolve o conceito de que em qualquer história fabricada se tem uma metodologia que influencia a seleção de determinados fatos em lugar de outros e de que a interpretação desses fatos não ocorre sem alguma inclinação teórica. O ponto crucial é: "qualquer historiador da ciência, que defende que o progresso da ciência é o progresso no conhecimento objetivo, utiliza uma reconstrução racional" (ibid., p. 192). Por exemplo, na explicação da revolução copernicana, tem-se uma classe importante de perguntas relacionadas a esta: "Por que razão as pessoas receberam/aceitaram as suas teorias como o fizeram?". Só pode responder a essa pergunta se for assumida explicitamente ou implicitamente uma resposta a outra pergunta em particular: 'Por que Kepler e Galileu aceitaram o núcleo duro do programa de Copérnico e rejeitaram a sua heurística platônica?". Sendo assim, qualquer resposta a esta última pergunta constituirá a coluna vertebral de uma interna reconstrução racional da história, sem a qual a história completa não pode ser escrita. Isso implica que a filosofia da ciência é primária e que a sociologia e a psicologia são secundárias ao se escrever a história da ciência. Exemplificando um historiador com a visão kuhniana, Lakatos (ibid., p. 190) afirma que ele não poderá fugir da tentação de "'cozinhar' uma história do monopólio de uma teoria (paradigma) e preparar um estado de 'crise' seguido por um 'momento de conversão"*.

Aliás, é importante ressaltar que mesmo que uma inclinação teórica possa ficar obscurecida por uma variação eclética de teorias ou pela confusão teórica, nem o ecletismo nem tal confusão equivalem a uma perspectiva não teórica. Aquilo que o historiador considera um problema externo constitui com frequência um excelente guia para sua metodologia implícita: alguns se perguntarão por que um fato puro ou uma teoria arriscada foram descobertos exatamente no momento e no lugar em que foram descobertos; outros se perguntarão por que uma mudança degenerativa de problemas pode gozar de uma ampla aceitação popular durante o período incrivelmente largo ou por que estava irracionalmentenecessitada de estimativa uma mudança progressiva de problemas. Qualquer investigação nesse sentido, porém, está condenada a vagar sem rumo até que se apresente uma definição de ciência segundo os princípios de alguma filosofia normativa da ciência (ibid., p. 120). Consequentemente, Lakatos defende que um dos mais interessantes problemas da história externa ${ }^{7}$ é a especificação das condições psicológicas e, certamente, sociais que são necessárias para tornar possível o progresso científico. No entanto, ele critica o fato de que elas nunca são suficientes pelo fato de que na simples formulação do problema externo é preciso que se inclua alguma teoria metodológica, alguma definição de ciência. Assim, a história da ciência é uma história de acontecimentos que são selecionados e interpretados de uma maneira normativa. Em resposta à crítica de Kuhn (1974) para a concepção de que a história é filosofia que fabrica exemplos, escreve: "Eu asseguro que todas as histórias da ciência são filosofias 
Contribuições da reconstrução racional didática no desenvolvimento de concepções epistemologicamente mais aceitáveis sobre a natureza da ciência e do progresso científico

que fabricam exemplos" (ibid., p. 192).

Dentro dessa perspectiva, ainda que se possa separar a história da filosofia da ciência, o presente estudo abraça o ponto de vista educacional mais prático e aplicado em que a história e filosofia da ciência (HFC) é pensada como estratégia didática facilitadora na compreensão de conceitos, modelos e teorias (MARTINS, 2007, p. 114). Valente (2005, p. 1), por exemplo, comenta que, embora se tenha hoje em dia alguma discussão sobre os perigos de se cair, no âmbito da educação científica, em uma pseudo-história (ALLCHIN, 2004), é possível interessar-se de outra forma pela história das ciências diferente daquela dos historiadores da ciência. Com base em algumas ideias sobre educação, do filósofo Whitehead, Valente (2005) estruturou um texto com os protagonistas Lavosier e Seguin, defendendo tal estruturação como um instrumento formativo importante, justificado na medida em que a pedagogia não se submete à história (ibid., p. 4).

Isso encoraja um professor das ciências naturais a trabalhar com as aproximações de padrões que são não históricos e lança uma saída para a aparente confusão entre escrever história ${ }^{8}$ e se usá-la em sala de aula ${ }^{9}$ É verdade que pode haver problemas em se escrever a história para servir a certos fins, por se tornar numa distorção da história. Escrever em função de uma necessidade, porém, não resulta simplesmente em pseudo-história (MATTHEWS, 1994) ${ }^{10}$. Seja como for, nesse sentido, um professor de ciência está usando uma aparente história explicitamemte para propósitos pedagógicos e, portanto, esse uso deve ser julgado segundo um critério diferente da pseudo-história ${ }^{11}$. Segundo Matthews (1995, p. 177), na pedagogia, a matéria (história da ciência) tem de ser simplificada e, nessa tarefa, mesmo que se queiram evitar distorções grosseiras, sem dúvida as boas intenções levarão a distorções.

Nesse sentido, Silva et al. (2008a) denominam RRD o uso da HFC como um ponto de partida para se desenvolverem e se projetarem soluções didáticas satisfatórias (MÄNTYLÄ \& KOPONEN, 2007), que podem se entendidas como reconstruções didáticas para auxiliar o ensino de conceitos científicos (IZQUIERDO-AYMERICH \& ADÚRIZ-BRAVO, 2003). É preciso dizer que, embora a RRD baseie-se na história e filosofia da ciência ao ser elaborada, essas bases são usadas como recursos, pois a intenção não é a obtenção de reconstruções históricas completamente autênticas. Ao invés disso, de acordo com Mäntylä e Koponen (2007, p. 292), "a bistória é interpretada do ponto de vista de concepções modernas, porque a meta, afinal de contas, é ensinar física, não a história da física". Aliás, o pensamento de que o conhecimento científico escolarizado atual deve ser a meta do processo de ensino e de aprendizagem, estando acima do ponto de vista de um ensino historicamente autêntico, tem sido amplamente defendido para o ensino de ciências (MÄNTYLÄ \& KOPONEN, 2007, p. 297-298; FEYERABEND apud PEREIRA \& AMADOR, 2007, p. 193; VALENTE, 2005, p. 4; IZQUIERDO-AYMERICH \& ADÚRIZ-BRAVO, 2003, p. 29; NIAZ \& RODRÍGUEZ, 2002, p. 62; 
DOBSON, 2000, p. 1). Todavia, a RRD procura manter um compromisso com alguns detalhes históricos que se encontram divulgados na literatura como as concepções dominantes, as atividades experimentais e os principais protagonistas. Por consequência da RRD inspirar-se também em aspectos da epistemologia de Lakatos (1978), este estudo parte da premissa de que o uso didático da HFC assim pensado tem um potencial de contribuir para auxiliar a evitar alguns dos entendimentos distorcidos sobre a natureza da ciência no ambiente escolar aqui já comentados.

\section{A RECONSTRUÇÃO RACIONAL DIDÁTICA DE SILVA et al. (2008a), SUA INSER- ÇÃO EM SALA DE AULA E METODOLOGIA DE ANÁLISE DE DADOS}

De acordo com Lakatos (1978), a reconstrução de um episódio histórico via inspiração em uma filosofia da ciência deve obedecer a certas metodologias normativas pelas quais é possível oferecer uma explicação racional do desenvolvimento do conhecimento científico. Na elaboração de uma RRD, portanto, é necessário omitir tudo o que é irracional diante da teoria da racionalidade adotada, selecionando-se fatos que são metodologicamente interpretados. Mais ainda, é possível adaptar comentários compatíveis com os programas científicos rivais nessa elaboração, como a pitada de sal lakatosiana ${ }^{12}$. Assim, conforme Silva et al. (2008a), a RRD com fins instrucionais obedeceu aos seguintes aspectos: 1) teorias rivais - deve haver pelo menos duas posições rivais e sucessivas; 2) núcleo teórico constituido por postulados - a base de uma teoria é constituída por postulados que devem ser apresentados como difíceis de serem refutados/abandonados, pois neles os cientistas depositam grande confiança; 3) contraexemplos que mostrem dificuldades teóricas e hipóteses auxiliares - por meio de tais dificuldades, tem-se o surgimento de hipóteses/explicações auxiliares, entendidas como tentativas para se obter sucesso na busca de manter as concepções nucleares protegidas de refutação; 4) critério de avaliação de teorias - caracteriza-se a aceitação da teoria sucessora pelo critério do grau de explicações sem contradição com os seus postulados, em analogia à degeneração da sua rival na proliferação de fatos contraditórios, isto é, resultados experimentais interpretados como incongruentes (LAKATOS, 1978, p. 77) ${ }^{13}$. A avaliação não ocorre entre a teoria e a experiência, sendo esta última juíza para a primeira, mas com testes entre, pelo menos, duas teorias e a experiência. É somente após o surgimento de uma teoria rival sucessora, que explique o êxito de sua rival e a suplante por uma demonstração adicional de força heurística, que se valida a superação de uma teoria por outra.

A RRD, normativamente assim elaborada, constituiu-se de um texto ${ }^{14}$ de aproximadamente duas páginas e foi aplicada nas quarta e na quinta aulas iniciais do ano letivo de uma turma do segundo ano do ensino médio, na disciplina Física, de um colégio estadual da região central da cidade de Londrina-PR. A discussão no texto procurou confrontar as explicações e hipóteses auxiliares dos programas 
Contribuições da reconstrução racional didática no desenvolvimento

de concepções epistemologicamente mais aceitáveis sobre a natureza da ciência e do progresso científico

rivais do calórico e cinético-molecular em fenômenos de aquecimento ${ }^{15}$, em que havia transferências e transformações de energia. Durante o estudo da RRD, o professor realizou reflexões com os estudantes de exemplos de critérios utilizados no cotidiano para decidir o que considerar numa situação, exemplos estes que serviram para auxiliar o entendimento de como avaliar programas rivais por um determinado critério racional que estava na $\mathrm{RRD}^{16}$. Também houve a necessidade de se fortalecerem entendimentos nos estudantes sobre as funções que uma teoria apresenta de explicar e prever os fenômenos.

Em analogia ao "sinal típico de degeneração de um programa, que é a proliferação de 'fatos' contraditórios” (LAKATOS, 1978, p. 77), já mencionado, o estudo da RRD confrontou as explicações/previsões das hipóteses auxiliares dos programas rivais do calórico e cinético-molecular em fenômenos de aquecimento, com o objetivo de alcançar uma interpretação da proliferação de fatos contraditórios à teoria do calórico, isso por estabelecer fenômenos de aquecimento por meio do atrito cujas interpretações permitem contradições com aquelas em que a teoria do calórico se viu igualmente fortalecida à rival cinético-molecular em fenômenos de trocas de calor (portanto, por diferença de temperatura) ${ }^{17}$. Já com a teoria cinético-molecular não se estabeleceu a interpretação de tal proliferação. Logo, analogamente, procurou-se um entendimento de degeneração (enfraquecimento) de uma teoria frente a outra, em que a lição que a RRD objetivou fornecer fundamentou-se no critério do grau de explicações sem contradição.

Dessa realização, uma avaliação ${ }^{18}$, para averiguar os efeitos do uso da RRD em auxiliar o processo de instrução com debates racionais, foi divulgada em Silva et al. (2008b). Diferentemente, aqui, são analisados os efeitos do uso da RRD nas concepções dos estudantes sobre a natureza das teorias científicas, utilizando-se o referencial de Vásquez e Massareno (1999). Esses autores pesquisaram as atitudes e convicções dos estudantes nos diversos níveis de ensino (do ensino básico até a universidade) sobre algumas características do conhecimento científico, tais como a natureza dos modelos científicos, a natureza do método científico, a influência social no conhecimento científico e as controvérsias dentro da comunidade científica (ibid., p. 377). Para isso, eles elaboraram questões a respeito da natureza da ciência, em que cada uma expressava uma afirmação e uma negação sobre um determinado aspecto dessa natureza.

Semelhantemente a este último trabalho, porém limitando-se a menos aspectos da ciência a serem analisados, na metodologia aqui utilizada solicitou-se dos estudantes que emitissem dois tipos de respostas para cada uma das duas questões $^{19}$. Primeiramente, os estudantes deveriam assinalar, entre duas alternativas disponíveis, com qual aspecto das explicações científicas eles concordavam. As alternativas de cada questão foram elaboradas de modo que um acordo com uma delas implica num desacordo com a outra. Em segundo lugar, após selecionar a alternativa que mais se identificava com suas crenças, o estudante deveria justi- 
ficar a razão de seu acordo ou desacordo com um dado aspecto. Pelas justificativas apresentadas nessas duas questões, analisaram-se as tendências para alguns pontos contrários que elas procuraram revelar a respeito da natureza das teorias científicas, como seu caráter provisório ou definitivo, realista ou instrumentalista e acumulativo ou evolucionista. É necessário dizer que essa análise é limitada, ou seja, que os comentários dos estudantes às duas questões não permitem que se desenvolvam, em detalhes, características da ciência configuradas por uma epistemologia específica. Por meio das duas questões, procura-se interpretar se os estudantes apresentam concepções com algumas características compatíveis para a visão de ciência positivista ou pós-positivista. De um lado, uma concepção das teorias científicas que é compatível com o positivismo apresentará características de um conhecimento científico definitivo e realista, em que o desenvolvimento do conhecimento ocorre por acumulação àquilo que já existe. Há uma concepção de conhecimento científico como sendo definitivo ou invariável, caracterizada por considerar as teorias científicas sendo verdades definitivas e absolutas. Por outro lado, uma concepção das teorias científicas que é compatível com as ideias pós-positivistas apresentará características de um conhecimento científico provisório e instrumentalista, em que o desenvolvimento do conhecimento pode ocorrer no abandono de uma teoria científica por outra capaz de substituí-la. Nessa análise, as duas questões proporcionaram um cruzamento das respostas, pois um acordo ou desacordo com um aspecto na primeira questão está, respectivamente, coerente com um acordo ou desacordo com um outro aspecto da segunda questão.

Relativos a essas duas questões, foram selecionados os resultados de oito estudantes anonimamente numerados e discutidos individualmente, sendo estes exemplos típicos que representam uma amostra de 23 estudantes participantes ${ }^{20}$. Os dados estão apresentados sem correções gramaticias e em forma itálica. Alguns comentários entre parênteses e de forma não itálica são do observador (primeiro autor deste manuscrito) e foram acrescentados aos comentários dos estudantes na intenção de se esclarecerem melhor estes últimos ao leitor.

\section{RESULTADOS}

As duas questões mencionadas nos dois últimos parágrafos da seção anterior são:

1. Pelo que você notou nas discussões históricas, as explicações científicas:

( ) baseiam-se em modelos que vão se aprimorando;

ou

( ) representam verdades inquestionáveis sobre a realidade?

Justifique.

2. Pelo que a história retratou é possivel afirmar:

( ) que as teorias físicas podem ser substituidas por outras que apresentam explicações para 
Contribuições da reconstrução racional didática no desenvolvimento

de concepções epistemologicamente mais aceitáveis sobre a natureza

da ciência e do progresso científico

um maior número de fenômenos;

ou

( ) que uma teoria física não pode ser substituída.

Justifique.

Antes dos resultados analisados, ainda é preciso salientar que, embora neles existam termos como "contradição", "inconsistência", "maior abrangência", "satisfação explicativa", entre outros, relacionados à forma individual dos estudantes expressarem suas convicções, Silva et al. (2008b) mostraram que esses termos carregam o seguinte entendimento comum: se uma hipótese ou tentativa de explicação entendida pelos estudantes sofresse a interferência de um argumento válido em que ela fosse reinterpretada como discordante de um pensamento básico de uma teoria correspondente (um postulado), essa explicação poderia ser rejeitada. Coerente com isso, em Silva (2008) tem-se análises globais dos raciocínios dos estudantes em uma estratégia de ensino ${ }^{21}$ em que eles admitiram como uma explicação satisfatória (sem contradição ou consistente) um pensamento análogo ao de uma hipótese auxiliar de um programa de pesquisa, isto é, uma explicação satisfatória entendida como uma explicação factual compatível com algum postulado teórico (núcleo). Assim sendo, esse entendimento, como resultado de uma lição implícita que a RRD alcançou em termos de avaliação normativa no uso de um critério de avaliação de teorias (SILVA 2008; SILVA et al. 2008b), não será aqui discutido nas análises, mas somente a tendência para os aspectos das concepções positivista ou pós-positivista já comentados, segundo o objetivo do estudo. Conforme se mencionou na introdução, a RRD origina-se de um estudo maior (SILVA, 2008) fazendo parte de um passo específico de uma estratégia de ensino constituída de sete passos e que, pelo objetivo do presente estudo, também não serão discutidos resultados relativos ao aprendizado dos conceitos científicos obtidos, pois estes estão divulgados em Silva et al. (2010). Ainda é preciso dizer que os passos anteriores dessa estratégia puderam garantir que os resultados apresentados a seguir são frutos das reflexões obtidas pelo estudo da RRD.

Estudante 1 - "(As teorias) São modelos que vão se aprimorando. A partir do momento que ela (uma teoria) se contradiz e começa a surgir outra que possa superá-la, ela começa a perder seu valor". Essa resposta, por admitir a possível situação de um programa degenerativo com menos valor em comparação com um rival progressivo, conduz à aceitação de que a RRD auxiliou o estudante a caminhar para um entendimento do processo de evolução do conhecimento na Física que não seja exclusivamente cumulativo e linear. Um outro comentário foi "Se uma teoria fosse verdade absoluta não surgiriam outras que a superassem". Essa resposta dá indícios de que a RRD auxiliou a promover o entendimento de que as teorias físicas não representam verdades inquestionáveis, como se elas pudessem caracterizar a imagem da realidade num espelho.

Estudante 2 - Esse aluno assumiu a postura de que as explicações científicas são

Rev. Ensaio | Belo Horizonte | v. 14 | n. 01 | p.65-80 | jan-abr | 2012 
modelos que se desenvolvem e permitem novas reflexões. Disse ele: "Em modelos que se aprimoram, uma vez que o mundo vive em intensa instabilidade e o homem, por sua ver, é um ser dotado de intelectualidade e capacidade psiquicas que lhe permitem uma nova reflexão a respeito desse mundo". Em conformidade com isso foi admitido que uma teoria pode ser substituída ("Sim (as teorias são substituíveis)"). Respondeu convicto: "Algum dia, possivelmente haverá fenômenos que a teoria cinético-molecular não saberá responder. Daí, haverá a necessidade de se estabelecer por intensos estudos uma nova teoria”. Essas respostas permitem a conclusão de que a RRD favoreceu um entendimento ao estudante de uma ciência cujas teorias não são invioláveis, mas falíveis e, por isso, podem ser substituídas por outras melhores, segundo o critério de avaliação de teorias por ele entendido.

Estudante 3 - "As teorias são colocadas em cheque conforme novas descobertas são feitas, então elas devem ser aprimoradas e, caso encontrem limitações para isso, novas teorias devem ser formuladas”. Esse comentário pode ser interpretado como se uma teoria dominante, ao se deparar com muitas anomalias, cedesse seu posto a uma nova teoria que necessitou ser formulada, o que é uma tendência para a visão kuhniana de ciência extraordinária do que lakatosiana. Porém, a outra resposta distancia-se da visão kuhniana ao retomar a essência da comensurabilidade entre os programas rivais da RRD. Isso é verificado pelo fato de o estudante resgatar o critério por ele assimilado do grau de explicações consistêntes ao afirmar "Teorias que apresentam inconsistência ao explicar fenômenos (explicações contraditórias) não têm muita utilidade para o homem. Teorias que explicam o maior número de fenômenos (coerentemente) satisfazem mais nessa incessante busca de respostas". Essa resposta permite dizer que um importante benefício didático da RRD foi o favorecimento do entendimento de uma constante possibilidade de o conhecimento científico encontrar-se inacabado.

Estudante 4 - Pode-se dizer que o estudante entendeu que a teoria do calórico era a teoria dominante e que, devido aos seus problemas explicativos, a teoria rival cinético-molecular pôde substituí-la. Assim comentou: "Pelas dúvidas (questionamentos) da teoria do calórico que fortaleceu a teoria cinético-molecular. As teorias são reformuladas conforme (as interpretações dos) os fenômenos e conforme as experiências com os resultados obtidos". "Mesmo que a Teoria Cinético-Molecular explique de forma mais abrangente os fatos, a Teoria do Calórico não foi esquecida, atéporque estou estudando as duas teorias agora". Esse comentário revela o entendimento de que a teoria cinético-molecular pode não estar inteiramente acabada, pois apenas é "mais abrangente" e, juntamente com o seu comentário anterior, pode-se interpretar que o pensamento do estudante compatibiliza com o de teorias em competição e que apresentam limitações explicativas.

Estudante 5 - Uma das bases do progresso científico é o caráter acumulativo do corpo de conhecimentos à medida que são construídos. Identifica-se essa característica na resposta "As teorias vão tentando, cada vez. mais, explicar fenômenos ocorridos. E podem se aprimorar por conseguir explicar de forma satisfatória esses fenômenos". No en- 
Contribuições da reconstrução racional didática no desenvolvimento de concepções epistemologicamente mais aceitáveis sobre a natureza da ciência e do progresso científico

tanto, o próximo comentário revela que o estudante não adquire uma concepção exclusivamente cumulativa do progresso científico: "Pois uma teoria é certa (aceita) até que entre outra, com (interpretação dos) resultados mais aceitáveis e (que) contrarie essa teoria (a primeira). Um exemplo é a (teoria) Cinético-Molecular substituir a Teoria do Calórico”. Dessas respostas, pode-se afirmar que a RRD é coerente com um ensino fundamentado em uma visão de ciência cujo progresso linear por acumulação é apenas uma simplificação da história vista somente num programa de pesquisa, em que esse tipo de progresso é rompido quando um programa é substituído. Estudante 6 - Pode-se notar o entendimento que vai ao encontro do ponto de vista que assume a mutabilidade das teorias científicas. Assim ele comentou: "(As teorias partem) de modelos (que) vão sempre se aprimorando, pois começam a surgir novas perguntas e novos testes e, se uma teoria não dá conta de explicar esses testes (resultados) $e$ perguntas, essa teoria deve ser aprimorada ou substituida por outra que (os) explique". "Essas teorias sempre estão sujeitas a mudanças, quando não conseguem explicar satisfatoriamente um fenômeno, elas vão enfraquecendo, e se surgir outra teoria que explique esse fenômeno satisfatoriamente, ou que explique mais fenômenos, essa teoria substitui a primeira”. Pode-se ver que o estudante admite o entendimento no qual um programa de pesquisa não é abandonado simplesmente por se tornar degenerativo, mas quando se tem um outro disponível ("e se surgir outra teoria") com o êxito explicativo do primeiro e mais um acréscimo de fenômenos explicados satisfatoriamente. É possível dizer que a RRD fez com que o estudante adquirisse um entendimento semelhante ao da seguinte situação: não deve haver rejeição ou falsificação de uma teoria antes do aparecimento de uma outra melhor capaz de substituí-la.

Estudante 7 - "As teorias se baseiam em modelos que vão se aprimorando, pois ela $(\mathrm{s})$ pode $(\mathrm{m})$ encontrar fenômenos que não podem ser explicados, então ela(s) vão se aprimorando até satisfazer(em) a explicação de todos fenômenos ocorridos ou da maioria”. Esse comentário sobre a natureza das teorias na ciência está em um sentido oposto ao da visão de ciência pronta, acabada e imutável. Pode-se dizer que a RRD, da forma como foi trabalha$\mathrm{da}$, auxiliou a desmistificar o entendimento ingênuo no qual as teorias representam uma imagem da realidade em um espelho. Pode-se notar ainda que o estudante mostrou uma compreensão do caráter limitado das explicações que as teorias fornecem, como visto em seu comentário sobre a teoria do calórico: "A Teoria do Calórico explica até um certo ponto. E a cinético-molecular consegue supri-la, assim sendo considerada mais apropriada".

Estudante 8 - Em relação à natureza das teorias científicas, o estudante opinou: “(As teorias partem) de modelos que vão se aprimorando". Nesse sentido, pode-se mostrar que a RRD promoveu um entendimento no estudante de que o conhecimento científico não é algo consumado, constituído por teorias sólidas e inabaláveis, como se nota em seu comentário de que a própria teoria cinético-molecular também pode vir a ser substituída: "Neste caso, a (teoria) cinético (molecular) substituiu a (teoria) calórica por apresentar melhores explicações para mais fenômenos e (no entanto), 
Osmar Henrique Moura da Silva | Carlos Eduardo Laburú

Roberto Nardi

a qualquer momento, ela (teoria cinético-molecular) também pode (vir a) ser substituida”.

\section{CONCLUSÃO}

A RRD, divulgada em estudos anteriores (SILVA, 2008; SILVA et al., 2008a e 2008b), não objetiva ser uma solução didática para a instrução de algum aspecto filosófico sobre a natureza da ciência, mas uma etapa, em uma estratégia de ensino, que busca auxiliar um aprendizado mais racional de conceitos científicos. Entretanto, não se pode escapar de uma possível influência educacional em alguns aspectos sobre a natureza do conhecimento estudado e que, sendo assim, procurou-se aqui investigar qual é.

Este estudo partiu da preocupação com uma concepção dogmática e distorcida sobre a natureza da ciência que pode comumente vir a predominar nos estudantes quando há um despreparo educacional nesse sentido. Essa concepção vê a ciência como uma coleção de leis que se cumprem com precisão e infalibilidade absolutas, em que o progresso científico é caracterizado linearmente por acumulação ao que já foi construído. Em sentido contrário, os resultados obtidos permitem dizer que o uso da RRD pode contribuir para favorecer entendimentos, de modo geral, compatívies aos seguintes: o mundo é cognoscível, mas a ciência não tem respostas para todas as perguntas e é mutável; teorias, leis e modelos apresentam validez com limitações; na ciência podem existir teorias rivais em competição que predizem resultados contraditórios sobre um mesmo fenômeno, sendo imperfeitas, incabadas. Já para a visão de progresso científico, pôde-se evidenciar que a filosofia educacional normativa proposta na elaboração da RRD não fortalece entendimentos de caráter exclusivamente acumulativos, o que provavelmente ocorreria em um conto simplificado da história que considerasse um único programa de pesquisa.

Por fim, as consequências investigadas aqui vão ao encontro da concepção educacional mais epistemologicamente aceitável sobre a natureza da ciência como algo potencialmente provisório, variável e controverso, e que assim revelam um ponto a favor do uso da RRD como uma alternativa viável; tendo em conta que ela assume uma função secundária no sentido investigado neste estudo.

\section{NOTAS}

${ }^{1}$ No caso, ao se trabalhar com um pouco de história da ciência envolvendo leis de Newton, princípio de Huygens, entre outros temas, uma discussão pode gerar uma conexão indesejada entre, por exemplo, o princípio de Huygens e sua elaboração. Segundo Whitaker (ibid., p. 108): "o estudante pode inferir que a conseqüência (princípio) era óbvia a Huygens, on 'imediatamente óbvia' para qualquer pessoa inteligente, por Huygens produzir seu princípio, considerando que fora assim pelo resultado de repetidas experi- 
Contribuições da reconstrução racional didática no desenvolvimento de concepções epistemologicamente mais aceitáveis sobre a natureza da ciência e do progresso científico

ências em laboratório (como também para a completa teoria ondulatória da lus)". ${ }^{2}$ Comte expressava esse significado ao afirmar: "Considerada na sua acepção mais antiga e mais comum, a palavra positivo designa o que é real em oposição ao que é quimérico" (ABBAGNANO, 2000 ,p. 777).

${ }^{3}$ As aproximações realizadas são limitadas, pois não se quer dizer que a visão de ciência de educadores e estudantes filosoficamente despreocupados seja a positivista.

${ }^{4}$ Isso ocorre porque o positivismo passou a ser rejeitodo no plano filosófico (CHALMERS, 1994, p. 97; KOIRÉ apud LAKATOS, 1978, p. 9), por, em geral, caracterizar-se no método empírico-indutivista e, na visão do conhecimento científico, como algo acabado/definitivo e que cresce por acumulação.

${ }^{5}$ Os detalhes sinteticamente organizados sobre a epistemologia de Lakatos (1978) podem ser vistos em Silva et al. (2008a).

${ }^{6}$ Alguns historiadores buscarão o descobrimento de fatos puros e generalizações indutivas, outros buscarão teorias arriscadas e experimentos cruciais negativos, outros buscarão grandes simplificações, ou mudanças progressivas e degenerativas de problemas, e assim por diante. Ainda que encontrá-los seja outra questão, qualquer historiador carrega alguma 'inclinação’ teórica.

${ }^{7}$ Para Lakatos (ibid.), a história interna ou reconstrução racional prevalece sobre a história externa porque a maioria dos problemas importantes da história externa se define mediante a história interna.

${ }^{8}$ Conforme Martins (2001).

${ }^{9}$ Aliás, Matthews (1994, p. 79) afirma que um professor de Ciência não é comprometido com essa tarefa.

${ }^{10}$ Coerentemente a isso, sem dizer que qualquer história seja válida, uma extensa discussão a respeito de inserções no ensino médio de componentes históricos e filosóficos em disciplinas das ciências naturais pode ser vista em Silva e Laburú (2010). ${ }^{11}$ Silva (2008) gasta mais de quinze páginas em discussões com argumentos contra e a favor tanto da inserção da história da ciência quanto de versões distorcidas da história e conclui: "Diante das controvérsias para o ensino, é impossivvel dizer que a inserção de conteúdos de história da ciência produzirá avanços notáveis e não trará problemas, mas também é impossivel dizer que as versões distorcidas da história são em si perniciosas e devem ser abolidas. Assim, continua sendo perfeitamente legítima a expectativa de que o uso de versões distorcidas venha a contribuir para a melhoria do ensino de conceitos cientificos" (ibid., p. 46).

${ }^{12}$ Essa condição talvez seja o aspecto mais controverso das ideias de Lakatos devido à consequente liberdade com que muitos enunciados podem ser adaptados numa reconstrução racional de um episódio histórico. Um exemplo refere-se à reconstrução racional do programa de Bohr. Nela, Lakatos sugere que se pode atribuir a ideia de giro do elétron corretamente a Bohr em 1913. O interessante é que mesmo pelo fato de seguramente saber que Bohr era bastante céptico da ideia de giro ainda em 1925, Lakatos afirma que essa ideia era compatível com o programa 
de pesquisa implicado pelo átomo de Bohr. Apesar de Bohr não ter pensado nisto (ou ao menos deixado explícito), Lakatos destaca que esta é uma reconstrução racional e que, nesse sentido, "alguns enunciados não devem ser tomados com uma pitada, senão com toneladas de sal" (LAKATOS, 1978, p. 55).

${ }^{13}$ Lakatos (ibid.) comenta que Michelson se manteve fiel ao éter até o fim: "viu-se principalmente frustrado pela incompatibilidade dos fatos que obteve por intermédio das suas mensurações ultraprecisas. Sua experiência de 1887 'mostrou' que não havia vento de éter sobre a superfície da terra. Mas a aberração 'mostrou' que havia (vento de éter)”. Ademais, Lakatos (ibid.) ainda comenta que "sua própria experiência (de Michelson) de 1925 (ou nunca mencionada ou, como no trabalho de Jaffe de 1960, 'Michelson and the Speed of Light', apresentada incorretamente) também 'provou' que havia (vento de éter)".

${ }^{14}$ Que pode ser encontrado em Silva (2008).

${ }^{15}$ Por trocas de calor e por atrito. Principalmente, pela teoria do calórico, gerando interpretações de hipóteses auxiliares e dificuldades explicativas em aquecimentos por atrito, baseando-se nas fontes: Basso e Fasolo (1968); Dampier (1945).

${ }^{16} \mathrm{Em}$ Silva et al. (2008a) tem-se uma analogia entre alguns aspectos do fazer ciência, inspirados em Lakatos (1978), e os de ensinar ciência. Para Lakatos (ibid., p. 32), a força heurística refere-se à capacidade de um programa em antecipar teoricamente fatos novos, como, também, recém interpretados em seu crescimento. Mas ele (ibid.) ressalta que um fato novo pode ser um fato improvável, ou mesmo proibido por outra teoria rival. Na RRD, é com esta última caracterização de um fato novo - explicar um fato proibido por uma teoria rival - que a inspiração no critério de força heurística torna-se mais forte para avaliar como progresso ou degeneração.

${ }^{17}$ No caso da teoria do calórico, as explicações para fenômenos de equilíbrio térmico não foram discutidas e entendidas como contraditórias com os postulados dessa teoria, em que proposições factuais foram interpretadas pela transição de calórico do corpo mais quente para o corpo mais frio e não pela criação de calórico. Detalhes de previsões, hipóteses e contra-exemplos realizados nas discussões com a RRD podem ser encontrados em Silva et al. (2008b).

${ }^{18}$ Constituído basicamente pelas questões: "1) Com cada uma das teorias, quais as explicações para o fenômeno de dois corpos a diferentes temperaturas atingirem, após um tempo de contato físico, a mesma temperatura? 2) Pelo que se estudou no texto de história, a teoria do calórico teve problemas explicativos? Explique. 3) A teoria do calórico consegue explicar o processo de aquecimento obtido com o atrito? Explique. E a teoria cinético-molecular? Explique. 4) Qual(is) critério(s) você utiliza para verificar se uma teoria é melhor que outra? 5) Compare as explicações que você deu e avalie entre as duas teorias rivais, a do calórico e cinético-molecular, qual delas pode ter maior sucesso explicativo. Justifique. Você acha que uma teoria pode ser melhor que outra? Justifique".

${ }^{19}$ Apresentadas no início da próxima seção.

${ }^{20}$ Havia 31 alunos então matriculados no curso.

${ }^{21}$ Tendo como quarto passo a inserção da RRD do presente estudo. 
Contribuições da reconstrução racional didática no desenvolvimento de concepções epistemologicamente mais aceitáveis sobre a natureza da ciência e do progresso científico

\section{BIBLIOGRAFIA}

ABBAGNANO, N. Dicionário de Filosofia. Editora Martins Fontes: São Paulo, 2000.

ALLCHIN, D. Pseudohistory and pseudoscience. Science \& Education, v.13, pp. 179-195, 2004. BASSO, D.; FASOLO, P. Física 1 - novo programa para o ensino de Física. Porto Alegre: Editora Sulina, 1968.

BLANCO, R.; NIAZ, M. Baroque tower on gothic base: a lakatosian reconstruction of student's and teachers' understanding of structure of the atom. Science \& Education, 7: pp. 327-360, 1998.

CHALMERS, A. F. A Fabricaşão da Ciência. São Paulo: Editora Unesp, 1994.

DAMPIER, W. C. História da Ciência - e das suas relações com a filosofia e a religião. $2^{\mathrm{a}}$ edição. Lisboa : Editorial Inquérito Limitada, 1945.

DELIZOICOV, D. Editorial - Sobre a produção do conhecimento científico. Caderno Catarinense de Ensino de Física, v. 13, n. 3: pp. 182-183, dez. 1996.

DOBSON K. Is physics debatable? Physics Education, v.35, n.1 (2000).

HARRIS, J. B. S. Uma revisão de pesquisas nas concepções de professores sobre a natureza da ciência e suas implicações para o ensino. Investigações em Ensino de Ciências, v. 4, n. 3: pp. 197-211 (1999).

IZQUIERIDO-AYMERICH, M.; ADÚRIZ-BRAVO, A. Epistemological Foundations of School Science. Science \& Education 12, pp. 27-43 (2003).

KUHN, T. 'Notas sobre Lakatos'. In Lakatos, Imre et al. - História de la ciencia y sus reconstrucciones racionales, pp. 79-95. Tecnos: Madrid, 1974.

KUHN, T. A Estrutura das Revoluções Científicas. $3^{\text {a }}$ edição. São Paulo: Editora Perspectiva S. A, 1994.

LAKATOS, I. The methodology of scientific research programmes. Philosophical Papers Volume 1. Cambridge: Cambridge University Press (1978).

MÄNTYLÄ, T.; KOPONEN, I. T. Understanding the Role of Measurements in Creating Physical Quantities: A Case Study of Learning to Quantify Temperatura in Physics Teacher Education. Science \& Education 16, pp.291-311 (2007).

MATTHEWS, M. R. Science Teaching - The role of history and philosophy of science. New York: Routledge (1994).

MATTHEWS, M. R. História, filosofia e ensino de ciências: a tendência atual de reaproximação. Caderno Catarinense de Ensino de Física, v. 12, n. 3: pp. 164-214, dez. 1995.

MARTINS, A. F. P. História e filosofia da ciência no ensino: há muitas pedras nesse caminho... Caderno Brasileiro de Ensino de Física, v. 24, n. 1: pp. 112-131, abr. 2007.

MARTINS, R. A. Como Não Escrever Sobre História da Ciência - um manifesto historiográfico. Revista Brasileira de Ensino de Física, v. 23, n. 1, mar. 2001.

MARTINS, R. A. Introdução. A história das ciências e seus usos na educação. In: SILVA, C. C. (Org). Estudos de História e Filosofia das Ciências: subsídios para aplicação no ensino. São Paulo: Editora Livraria da Física, 2006.

NIAZ, M. \& RODRÍGUEZ, M. A. Improving learning by discussing controversials in 20th century physics. Physics Education, pp. 59-63, jan. 2002. 
PEREIRA, A. I.; AMADOR, F. A história da ciência em manuais escolares de ciências da natureza. Revista Eletrônica de Enseñanza de las Ciências, v. 6, n. 1 (2007).

PONCZEK, R. L. Pode a Física ser um bom árbitro para questões epistemológicas? Caderno Brasileiro de Ensino de Fúsica, v. 26, n. 2: pp. 295-313, ago. 2009.

POPPER, K. A Lógica da Pesquisa Científica. São Paulo: Editora Cultrix, 1972.

SILVA, O. H. M. Um estudo sobre a estruturação e aplicação de uma estratégia de ensino de Física inspirada em Lakatos com a Reconstrução Racional Didática para auxiliar a preparar os estudantes para debates racionais entre teorias e/ ou concepções rivais. 2008. Tese (Doutorado em Ensino de Ciências e Educação Matemática) - Faculdade de Ciências, Universidade Estadual Paulista (UNESP), Bauru-SP. 2008.

SILVA, O. H. M.; NARDI, R.; LABURÚ, C. E. Uma estratégia de ensino inspirada em Lakatos com instrução de racionalidade por uma Reconstrução Racional Didática. ENSAIO, v. 10, n. 1, pp: 9-22, jul. 2008.

SILVA, O. H. M.; NARDI, R.; LABURÚ, C. E. Um estudo da preparação dos estudantes para debates racionais entre teorias e/ou concepções rivais numa estratégia de ensino de Física inspirada em Lakatos. ENS AIO, v. 10, n. 2, pp: 193-207, dez. 2008.

SILVA, O. H. M.; NARDI, R.; LABURÚ, C. E. Um estudo dos avanços conceituais dos estudantes sobre calor e temperatura decorrentes da aplicação de uma estratégia de ensino inspirada na teoria de Lakatos. Revista Eletrónica de Investigación em Educación en Ciencias. V. 5, n. 1: pp. 1-18, jul. 2010.

SILVA, O. H. M.; LABURÚ, C. E. Inserções de componentes históricos e filosóficos em disciplinas das ciências naturais no ensino médio: reflexões a partir das controvérsias historiográficas entre Kuhn e Lakatos. Revista Eletrónica de Investigación en Educación en Ciencias. V. 5, n. 2: pp. 69-81, dez. 2010.

SILVEIRA, F. L.; OSTERMANN, F. A insustentabilidade da proposta indutivista de "descobrir a lei a partir de resultados experimentais". Caderno Brasileiro de Ensino de Física, v. 19, número especial: pp. 7-27, jun. 2002.

VALENTE, M. Contributo da história e filosofia das ciências para o desenvolvimento do gosto pelo conhecimento científico. Enseñanza de las ciencias, número extra, VII Congresso (2005). Disponível em: <http://ensciencias.uab.es/webblues/www/congres2005/material/comuni_orales/1_ense_ciencias/1_3/Valente_865.pdf>. Acesso em: 6 de agosto de 2009. VÁSQUEZ, Á.; MASSARENO, M. A. Características del conocimiento científico: creencias de los estudiantes. Enseñanza de las ciências, 17 (3): pp. 377-395 (1999).

WHITAKER, M. A. B. History and Quasi-history in Physics Education - part 1. Physics Education 14: pp. 108-112 (1979).

Data de recebimento: 05/07/2010

Data de aprovação: $21 / 10 / 2010$

Data da versão final: 27/12/2010 